\title{
Belief and recollection of autobiographical memories
}

\author{
DAVID C. RUBIN \\ Duke University, Durham, North Carolina \\ ROBERT W. SCHRAUF \\ Northwestern University, Evanston, Illinois \\ and \\ DANIEL L. GREENBERG \\ Duke University, Durham, North Carolina
}

\begin{abstract}
In three experiments, undergraduates rated autobiographical memories on scales derived from existing theories of memory. In multiple regression analyses, ratings of the degree to which subjects recollected (i.e., relived) their memories were predicted by visual imagery, auditory imagery, and emotions, whereas ratings of belief in the accuracy of their memories were predicted by knowledge of the setting. Recollection was predicted equally well in between- and within-subjects analyses, but belief consistently had smaller correlations and multiple regression predictions between subjects; individual differences in the cognitive scales that we measured could not account well for individual differences in belief. In contrast, measures of mood (Beck Depression Index) and dissociation (Dissociative Experience Scale) added predictive value for belief, but not for recollection. We also found that highly relived memories almost always had strong visual images and that remember/know judgments made on autobiographical memories were more closely related to belief than to recollection.
\end{abstract}

Recollection, or a sense of reliving, is central to autobiographical memory. Baddeley (1992), Greenberg and Rubin (in press), and Rubin (1998) identified the reliving of the original experience as the defining feature of autobiographicalmemory. Brewer (1996), in a systematic classification of types of memory, noted that psychologists and philosophers often use recollection, or the reliving of the original experience, to distinguish autobiographical memory from other forms of memory. Similarly, Tulving (1983, 1985; Wheeler, Stuss, \& Tulving, 1997) noted that the retrieval of an episodic memory involves something more than simple conscious experience. Specifically, the rememberer must be presently conscious of a prior conscious experience, a mental state that Tulving has termed autonoeticconsciousness. Thus, recollection is used to distinguish autobiographicalmemory from other states, such

We thank John B. Carroll, Paolo Ghisletta, Judith Gluck, Will Fleeson, Robert Jackson, Ulman Lindenberger, Kevin Weinfurt, and Dan Wright for their statistical suggestions; Robert Belli, Dorthe Berntsen, Susan Bluck, Phil Costanzo, Herb Crovitz, and Tilmann Habermas for their comments on the project and manuscript; and NIA Grant RO1 AG16340 for support. Portions of this paper were presented at the FortyFirst Annual Meeting of the Psychonomic Society (2000). The paper was written in part when D.C.R. was a visiting scientist at the Max Planck Institute for Human Development, Berlin, and a visiting professor at the Psychology Department, University of Aarhus. Correspondence should be addressed to D. C. Rubin, Psychological and Brain Sciences, Aarhus University, Asylvej 4, 8240 Risskov, Denmark (e-mail: rubin@ psych.duke.edu). as imagining or dreaming, and from the retrieval of facts about the self.

Belief is also a basic feature of autobiographical memories (Brewer, 1996). Philosophers have noted that memory is a source of belief-provides justification for true belief - in much the way that sense knowledge or perception does (Conee, 1998; Ginet, 1980). Like perception, memory can at times deceive, occasioning false belief or doubt (e.g., Sheen, Kemp, \& Rubin, 2001). Studies of reality monitoring (Johnson, Foley, Suengas, \& Raye, 1988; Johnson, Hashtroudi, \& Lindsay, 1993; Johnson \& Raye, 1981; Mather, Henkel, \& Johnson, 1997), in which participants are asked to judge whether a remembered event really occurred and was not merely imagined, indicate that recollection and belief may be processed differently. Belief that the remembered event had actually occurred depended more on what Johnson and colleagues (1988) called contextual, as opposed to perceptual, information. In their study, recent real events differed from imagined events on all contextual ratings and only some perceptual ratings, thus hinting that belief emphasizes setting and context.

In order to inquire what properties predict the degree to which a memory will be recollected and believed, some theoretical stance about the key concepts is needed. We view autobiographical memories as the products of component processes, with each process occurring in a separate behaviorally and neurally defined system (Greenberg \& Rubin, in press; Rubin, 1995b, 1998, 2002; Rubin \& Greenberg, 1998, 2003; Schrauf \& Rubin, 1998, 2000). 
Available evidence suggests that these component processes are an integrative memory system, imagery in individual modalities as well as multimodal spatial imagery, language, narrative reasoning, and emotions. A full-blown autobiographical memory requires the integrative memory system, at least one modality-specific type of imagery (usually visual imagery), and, to varying degrees, spatial imagery, imagery in the other senses, narrative reasoning, and emotions. There is considerable support for this multiple-systems model behaviorally and neuropsychologically (Greenberg \& Rubin, in press; Rubin \& Greenberg, 1998), and the same multiple-systems model can explain other complex cognitive tasks such as memory for oral traditions (Rubin, 1995a, 1995b). Under this multiplesystems model, belief and recollection are not separate subsystems. Rather, they are meta-cognitive judgments that are based on the activity of other systems.

\section{Within- and Between-Subjects Analyses}

What properties predict the degree to which a memory will be recollected or believed? We ask this question at two levels of analysis. First, at the nomothetic level, we ask what causes a particular individual to vary on the degree to which he/she recollects and believes particular memories. Second, at the individual differences level, we ask what causes individuals to vary on the average degree to which they recollect or believe a sample of their autobiographical memories. Most theories in cognitive psychology are nomothetic; they are formulated to hold for every individual. They assume that although there may be some variation in the level of abilities among individuals, the relations among theoretical constructs are the same for all individuals. To our knowledge, this nomothetic assumption has never been tested before for studies of autobiographical memory, but we test it here by reporting on the similarity of correlations calculated within single individuals. There is another common form of analysis in psychology: idiographic research, or individual differences testing. Each subject provides an aggregate score on a number of scales. The analyses are not within individuals but between (or among) them. They are based on more stable, trait-like properties of individuals rather than the more state-like variation among responses studied in most of experimental psychology. The structure of responses within individuals is typically reported only in terms of the reliability of the scales.

Psychologists have long argued that combining nomothetic and idiographic research is important (Cronbach, 1957; Underwood, 1975). We make the unusual move, especially in cognitive psychology, of doing both within the same data set by using parallel correlational techniques. This approach raises the question of the relation between the two forms of analysis. As Cronbach noted, nomothetic research and idiographic research use as data what the other approach dismisses as error variance, and our study is no exception. But we can make a stronger claim. In Cattell's (1952, p. 502) terms, the nomothetic and individual differences correlations "have no necessary mathematical relation." Correlations are the same whether they are calculated on raw scores or on linear transformations of those raw scores, such as $z$-scores. Thus, when we calculate correlations within an individual, the mean value of that individual on each variable does not affect the results and can even be removed from the data by subtracting it from all observations. But it is exactly these mean values - and only these mean values - that we use for the individual differences, between-subjects analyses. Therefore, the within- and between-subjects analyses are independent of each other in the extreme sense that each can be based on information the other does not have.

We therefore treat the between- and within-subjects analyses as separate levels of analysis (Cattell, 1952). If we wanted to emphasize the nested structure of the memories within subjects and the individual subjects within a population of subjects (and to make added statistical assumptions), we could couch our analysis in a hierarchical linear models framework (Bryk \& Raudenbush, 1992; Wright, 1998). Similarly, we could use structural equation models or newer developments in p-technique analysis (see Nesselroade \& Molenaar, 1999) to develop a method of analysis that integrates the correlational techniques and levels of analysis used. Instead we applied standard statistical techniques more familiar to cognitive psychologists in order to concentrate on the findings at each level independently.

\section{Properties of Autobiographical Memories to be Measured}

Table 1 provides a description of our measures. The full questions are given in the Appendix.

Recollection and belief. As measured here, both recollection and belief are verbal reports of phenomenological states. Unless a person is trying to deceive, the statement that he/she is reliving a past experience or that he/she believes his/her memory to be true and accurate are the ultimate standards. One can ask whether the behavior or physiology is consistent with the person's report or how the form and context of the question affects the response (Schooler \& Fiore, 1997; Schwarz, 1990), but the report is the primary evidence. We formulated three rating scales intended to assess recollection. The first question asked whether the subjects felt as though they were reliving the original event. The second question, taken from work by Tulving and his colleagues (e.g., Wheeler et al., 1997), asked whether the memory came with a sense of mentally traveling back in time to the original experience. The third question asked whether the subjects could remember the event, or whether they simply knew it had happened (remember/know). We used a 7-point rating scale rather than a dichotomous choice in order to parallel the form of our other scales. We included reports of belief by asking our subjects to judge whether the event had really occurred in the way it was remembered, or whether some parts of the memory had been imagined (our real/imagine variable), whether they felt their memories were accurate in that they were what a neutral observer would remember, whether they could be persuaded to change their memory 
Table 1

Variables Used in Study

\begin{tabular}{|c|c|c|}
\hline Variable & Brief Description of Rating Scale & Experiments \\
\hline \multicolumn{3}{|c|}{ Recollection and Belief } \\
\hline Reliving & I am reliving the original event. & All \\
\hline Back in time & I travel back to the time when it happened. & All \\
\hline Remember/know & I remember it rather than just knowing it happened. & All \\
\hline Real/imagine & I believe the event in my memory really occurred. & All \\
\hline Persuade & I could be persuaded that my memory was wrong. & 3 \\
\hline Accurate & Distorted versus as accurate as a neutral observer. & 3 \\
\hline Testify & Would you be confident enough to testify in court? & 3 \\
\hline \multicolumn{3}{|c|}{ Component Processes } \\
\hline See & I can see it in my mind. & All \\
\hline Setting & I can recall the setting where it occurred. & All \\
\hline Spatial & I know the spatial layout. & 2,3 \\
\hline Hear & I can hear it in my mind. & All \\
\hline Talk & I or other people are talking. & All \\
\hline In words & It comes to me in words. & All \\
\hline Story & It comes to me as a coherent story. & All \\
\hline Emotions & I can feel now the emotions that I felt then. & All \\
\hline \multicolumn{3}{|c|}{ Reported Properties of Events or Memories } \\
\hline Importance & It is significant for my life. & All \\
\hline Rehearsal & I have thought or talked about this event. & All \\
\hline Once/many & It occurred once at one particular time. & All \\
\hline Merged/extended & A merging of events versus an extended event. & All \\
\hline Age of memory & Please date the memory (month/day/year). & All \\
\hline
\end{tabular}

(persuade), and whether they would be confident enough to testify in court on the basis of their memory. It is possible that participants might assume that each of our three questions about recollection and each of our four questions about belief targets different constructs, forcing differences among them that might not appear if each question were presented alone (Grice, 1975; Schwarz, 1990). We run this risk, however, both to represent different literatures that have articulated the same question around different metaphors (e.g., recollection using "reliving," "time travel," and "remember"/ "know") and to ensure the generality of our findings.

Component processes. The most important of the component processes involved in having and reporting an autobiographical memory that has been reported in the psychological and philosophical literatures is visual imagery (see Brewer, 1996; Greenberg \& Rubin, in press; Larsen, 1998; Rubin, 1998; Rubin, Burt, \& Fifield, in press; and Rubin \& Greenberg, 2003, for reviews). Visual imagery can be divided on both behavioral and neural grounds into two systems: object or descriptive imagery and spatial imagery. More colloquially, these comprise a "what" and a "where" system (Farah, Hammond, Levine, \& Calvanio, 1988; Rubin, 1995a). By using a rating scale that asks whether the event can be seen in the mind, we measure visual imagery with emphasis on its descriptive component (our see variable). We measure visual imagery with emphasis on the spatial component by asking whether the setting can be recalled, and whether the spatial layout is known. The latter two questions can also be seen as a measure of context or as one aspect of the genre of telling a coherent story.
We asked whether the memory can be heard in the mind (hear) to distinguish visual imagery from imagery in general because of the interest in auditory imagery (Reisberg, 1992) and because of the role of auditory imagery in language. Autobiographical memories often contain reports of language, and language is the most common way to communicate autobiographicalmemories. Because of the central role of language in cognition and in culture, and because of our interest in autobiographical memory in bilinguals (Larsen, Schrauf, Fromholt, \& Rubin, 2002; Schrauf, 2000; Schrauf \& Rubin, 1998, 2000), we included two questions on language that have an auditory imagery component. These questions ask whether people are talking in the memory (talk) and whether the memory comes in words. Because of the important role that narrative plays in autobiographical memory (see Rubin, 1995b, 1998 , for reviews), because narrative can be viewed as independent of language (Greenberg \& Rubin, in press; Rubin \& Greenberg, 2003), and because of the issue of narrative coherence in traumatic memories (Berntsen, Willert, \& Rubin, 2003; Rubin, Feldman, \& Beckham, in press), we ask subjects to report whether the memory was a coherent story or whether it came in isolated facts or observations, independent of whether the memory came mostly in words or in images.

In addition, it is clear that emotions play an important and actively researched role in autobiographical memory (Christianson \& Safer, 1996; Rubin \& Berntsen, 2003; Williams, 1996). Although many aspects of emotion could be queried, our interest in reliving led us to formulate a question that concentrated on whether the emotions of the original event were reinstated. 
Reported properties of events. We asked about the subject's judgment of the importance of the remembered event (Pillemer, 1998); that is, was it an anchor, critical juncture, or turning point in the subject's life? We also asked subjects to estimate the number of times they had previously thought about the memory, because rehearsal, especially spaced rehearsal, improves retention (Bahrick, 1979; Rubin, 1995a), varies for different types of cues (Rubin, Groth, \& Goldsmith, 1984), and in many models leads to the development of a schema or to the transfer from episodic to semantic memory.

Subjects judged whether the memory concerned a specific event that occurred once or whether it captured multiple similar occurrences. The distinction between single and multiple occurrences of an event leading to a single autobiographical memory is central to Tulving's (1972) early episodic-semantic memory distinction and is important for the study of autobiographical memory in depression and in posttraumatic stress disorder (McNally, Litz, Prassas, Shin, \& Weathers, 1994; Williams, 1996). We expanded the specific-event question to include three choices: whether the memory was for an event that occurred once within a single day (once/many) and, if not, whether it was a summary or merging of similar events, or whether it was for an event that extended for a period greater than 1 day (merged/extended). Memories of merged but not extended events increase in depression (Williams, 1996), and the 1day duration was taken from Williams's work. Finally, because of interest in the distribution of memories over the lifespan (Crovitz \& Schiffman, 1974; Rubin \& Schulkind, 1997; Schrauf \& Rubin, 1998) and because older memories might be less intense on all scales due to forgetting, we asked subjects to date their memories so we could calculate the age of memory.

This set of questions is our attempt to describe autobiographical memory. Each question is a proxy for one or more complex theoretical ideas. Different wordings or different questions might improve on those we have chosen, and the method allows for questions to be changed in future research to address issues or criticisms that arise. Nonetheless, the questions asked are a comprehensive, theoretically motivated set that covers central distinctions and processes in contemporary memory research. Though derived independently from questions we have used in studying autobiographicalmemory, most of our questions cover the same basic domains as the 39 questions of the Memory Characteristics Questionnaire developed to understand source monitoring (Johnson et al., 1988). In contrast, our Autobiographical Memory Questionnaire is much shorter, allowing us to obtain data on many memories from each subject, and includes questions about recollection.

\section{EXPERIMENT 1}

\section{Method}

Subjects. Fifty-five Duke University undergraduates who were native speakers of English participated. Two subjects were elimi- nated because they failed to produce memories to more than one word, and 3 subjects were eliminated for failing to date more than two memories. The mean age of the remaining 50 subjects was 18.54 $(S D=0.76$, range 17-21); 34 were female.

Materials. Each subject was presented with a booklet consisting of a cover page with instructions, a double-sided sample page containing the cue word tree and 15 questions about the memory it cued, a dividing page, and then 30 more double-sided pages, each of which contained one of 30 cue words and the 15 questions referring to the memory it elicited. The cue words were the 33 words that produced the least missing data in Rubin (1980), with the words ambulance, death, and hospital eliminated because of concern of eliciting painful memories. For half the subjects, the cue words were given in the following order: candy, city, doctor, dress, horse, friend, health, money, river, tobacco, window, lake, love, mother, party, plant, book, poetry, mountain, paper, kiss, water, anger, flower, church, dirt, ocean, sickness, fire, and wine. For the remaining subjects, the order was reversed. The 15 questions listed in the Appendix with an asterisk were given in the order presented in the Appendix. As noted in the Appendix, Question q was transformed into two measures here: once/many and merged/extended.

Procedure. The subjects were tested in two large groups. They were read the printed instructions and asked to think of a memory to the word tree and then answer all 15 questions about it. Each of the 15 questions was discussed briefly and any questions from the subjects were answered. The subjects were then asked to recall a memory to each of the remaining 30 cue words in turn and, while they were thinking about that memory, to answer the 15 questions about it. Although many factors can affect people's judgments about their memories (for reviews, see Cavanaugh, Feldman, \& Hertzog, 1998, and Schooler \& Fiore, 1997), ratings given while an activity is ongoing, in contrast to retrospective reports, reflect the cognitive processes involved in that activity in ways that produce lawful relations and relate in reasonable ways to objective measures (Ericsson \& Simon, 1993), and so we obtained our ratings while our subjects were being asked to remember each autobiographical memory. This part of the task was self-paced. The complete procedure took between 50 and $90 \mathrm{~min}$.

\section{Results}

Means and correlations. Because of missing values, the number of observations for each variable was between 1,492 and 1,498 instead of 1,500, except for merged/ extended, which had 470 observations because it considers only memories that were for events that lasted more than 1 day. The means for all variables are shown in Table 2. Because there are few missing values, one set of means suffices for both the between- and within-subjects analyses. The next three columns show the standard deviations and ranges for calculation done on the average value of each measure for each subject; there is substantial variability and range, allowing for individual differences analyses. The far-right column shows the average of the standard deviations within each individual (actually the square root of the average variance).

Table 3 presents the correlations among all variables calculated between subjects. It was computed by averaging the 30 observations of each subject to provide one value for each subject for each of the scales and then correlating these values over the 50 subjects. Thus, these correlations were calculated as individual differences measures and show whether subjects who on the average rated memories highly on one scale rated them highly on an- 
Table 2

Means and Standard Deviations of All Scales in Experiment 1

\begin{tabular}{|c|c|c|c|c|c|}
\hline \multirow[b]{2}{*}{ Variable } & \multicolumn{4}{|c|}{ Between Subjects } & \multirow{2}{*}{$\begin{array}{l}\text { Within } \\
\text { Subjects } \\
\text { SD }\end{array}$} \\
\hline & $M$ & $S D$ & Min & Max & \\
\hline Reliving & 4.83 & 0.80 & 3.30 & 6.60 & 1.43 \\
\hline Back in time & 4.85 & 1.09 & 1.10 & 6.43 & 1.50 \\
\hline Remember/know & 5.69 & 0.65 & 3.97 & 6.93 & 1.41 \\
\hline Real/imagine & 5.75 & 0.72 & 4.17 & 7.00 & 1.25 \\
\hline See & 5.37 & 0.72 & 3.57 & 6.83 & 1.33 \\
\hline Setting & 5.85 & 0.75 & 3.37 & 6.97 & 1.28 \\
\hline Hear & 4.23 & 0.96 & 2.47 & 6.03 & 1.71 \\
\hline Talk & 4.34 & 0.87 & 2.34 & 5.90 & 1.78 \\
\hline In words & 3.43 & 1.36 & 1.00 & 6.17 & 1.48 \\
\hline Story & 4.49 & 1.06 & 2.07 & 6.30 & 1.67 \\
\hline Emotions & 4.65 & 0.91 & 2.60 & 6.70 & 1.64 \\
\hline Importance & 3.51 & 0.88 & 1.80 & 5.83 & 1.85 \\
\hline Rehearsal & 3.41 & 0.81 & 1.70 & 5.67 & 1.65 \\
\hline Once/many & 0.69 & 0.15 & 0.30 & 0.97 & 0.45 \\
\hline Merged/extended & 0.43 & 0.27 & 0.00 & 1.00 & 0.45 \\
\hline Age of memory & 1,565 & 779 & 258 & 4,198 & 1,459 \\
\hline
\end{tabular}

Note-The standard deviations in the within column are the average of the standard deviations of the 30 subjects.

other. Reliabilities for these variables, as indexed by Cronbach's alpha, were uniformly high, ranging between .84 and .96 .

Table 4 presents the average within-subjects correlation. It was computed by considering the 30 observations of each subject separately. A correlation matrix of the form shown in Table 4 was calculated for each of the 50 subjects separately, and then each of the cells of these 50 matrices was averaged and entered into Table 4 . With the exception of correlations based on merged/extended, which has fewer observations, the .05 confidence intervals averaged \pm .06 around the mean values in Table 4 (range of \pm .04 to \pm .11 ; for merged/extended, the maximum was $\pm .14)$. To provide another measure of how well the subjects agree with each other, the number of subjects (out of 50) who had correlations in the same expected direction (positive for all correlations except those with age of memory) was noted. By chance, there would be an average of 25. For most of the correlations, there were fewer than 5 people whose correlations were in the wrong direction. For the 36 correlations from among the highly correlated variables of reliving, back in time, remember/know, real/ imagine, see, setting, hear, story, and emotions, only one correlation had more than 2 people whose correlations were in the wrong direction. Thus, examining either the variability in the individual subject's correlations or the agreement in his/her sign, the individual subject's correlations are similar to each other and well represented by the means of Table 4.

If one excludes the merged/extended variable, which has values only for those memories reported to span more than a day, there are 105 correlations shown in Tables 2 and 3. A standard way to provide a graphic approximation of such a large amount of information on a two-dimensional

Table 3

Correlations Among All Variables Calculated Between Subjects

\begin{tabular}{|c|c|c|c|c|c|c|c|c|c|c|c|c|c|c|c|}
\hline & Rel & $\mathrm{BiT}$ & $\mathrm{R} / \mathrm{K}$ & $\mathrm{R} / \mathrm{I}$ & See & Set & Hea & $\mathrm{Tlk}$ & InW & $\mathrm{Str}$ & Emo & Imp & Reh & $\mathrm{O} / \mathrm{M}$ & $\mathrm{M} / \mathrm{E}$ \\
\hline \multicolumn{16}{|l|}{ Reliving } \\
\hline Back in time & 76 & & & & & & & & & & & & & & \\
\hline Remember/know & 50 & 42 & & & & & & & & & & & & & \\
\hline Real/imagine & 35 & 40 & 73 & & & & & & & & & & & & \\
\hline See & 78 & 60 & 64 & 35 & & & & & & & & & & & \\
\hline Setting & 59 & 41 & 68 & 45 & 84 & & & & & & & & & & \\
\hline Hear & 69 & 51 & 35 & 11 & 61 & 41 & & & & & & & & & \\
\hline Talk & 55 & 50 & 37 & 18 & 53 & 48 & 84 & & & & & & & & \\
\hline In words & 24 & 19 & 18 & 10 & 15 & 10 & 31 & 30 & & & & & & & \\
\hline Story & 54 & 57 & 52 & 36 & 50 & 42 & 53 & 58 & 53 & & & & & & \\
\hline Emotions & 74 & 53 & 22 & 06 & 59 & 52 & 61 & 62 & 03 & 41 & & & & & \\
\hline Importance & 47 & 43 & 11 & 05 & 26 & 16 & 39 & 34 & 16 & 28 & 50 & & & & \\
\hline Rehearsal & 34 & 33 & 12 & 11 & 15 & 06 & 41 & 43 & 24 & 38 & 44 & 68 & & & \\
\hline Once/many & -04 & 01 & 03 & 27 & -02 & 04 & -07 & 07 & 26 & 29 & -01 & -14 & 10 & & \\
\hline Merged/extended & -15 & -04 & -09 & 09 & -25 & -14 & -06 & 08 & -06 & 14 & -03 & 07 & 23 & 25 & \\
\hline Age of memory & -22 & -15 & -12 & -10 & -32 & -38 & -16 & -23 & -06 & -11 & -17 & 06 & 07 & -12 & -10 \\
\hline
\end{tabular}


Table 4

Correlations Among All Variables Calculated Within Subjects

\begin{tabular}{|c|c|c|c|c|c|c|c|c|c|c|c|c|c|c|c|}
\hline & Rel & $\mathrm{BiT}$ & $\mathrm{R} / \mathrm{K}$ & $\mathrm{R} / \mathrm{I}$ & See & Set & Hea & Tlk & InW & Str & Emo & $\operatorname{Imp}$ & Reh & $\mathrm{O} / \mathrm{M}$ & $\mathrm{M} / \mathrm{E}$ \\
\hline \multicolumn{16}{|l|}{ Reliving } \\
\hline Back in time & 65 & & & & & & & & & & & & & & \\
\hline Remember/know & 60 & 59 & & & & & & & & & & & & & \\
\hline Real/imagine & 54 & 54 & 62 & & & & & & & & & & & & \\
\hline See & 66 & 58 & 61 & 51 & & & & & & & & & & & \\
\hline Setting & 53 & 50 & 62 & 49 & 58 & & & & & & & & & & \\
\hline Hear & 63 & 54 & 52 & 43 & 57 & 44 & & & & & & & & & \\
\hline Talk & 46 & 45 & 42 & 36 & 44 & 38 & 60 & & & & & & & & \\
\hline In words & 33 & 33 & 31 & 29 & 28 & 26 & 38 & 35 & & & & & & & \\
\hline Story & 56 & 63 & 54 & 53 & 49 & 46 & 51 & 46 & 39 & & & & & & \\
\hline Emotions & 60 & 56 & 49 & 45 & 51 & 44 & 53 & 43 & 34 & 54 & & & & & \\
\hline Importance & 42 & 41 & 31 & 33 & 31 & 27 & 37 & 30 & 30 & 42 & 52 & & & & \\
\hline Rehearsal & 39 & 37 & 32 & 29 & 32 & 27 & 36 & 33 & 31 & 40 & 44 & 55 & & & \\
\hline Once/many & 11 & 09 & 11 & 12 & 11 & 10 & 10 & 13 & 03 & 17 & 07 & 01 & -02 & & \\
\hline Merged/extended & 15 & 12 & 13 & 15 & 17 & 09 & 09 & 06 & 14 & 22 & 17 & 22 & 28 & - & \\
\hline Age of memory & -40 & -38 & -38 & -44 & -36 & -32 & -36 & -28 & -26 & -39 & -34 & -19 & -17 & -13 & 02 \\
\hline
\end{tabular}

Note-Decimals omitted. The order of abbreviations at the top follows the order of the left column. For the real/imagine variable, 2 subjects always answered 7, so they provided no within correlations for this variable and the $n$ for this variable is 48 . One of these subjects always answered 1 for the in words variable and so the $n$ for this variable is 49 .

page is to use a principal components analysis with a twofactor solution, as shown in Figure 1. The two axes are independent linear combinations of the 15 variables that retain as much of the relationships of the full correlation tables as possible. The top panel corresponds to the betweensubjects correlations of Table 3 . The bottom panel corresponds to the within-subjects correlations of Table 4. The figure captures many of the relations shown in the tables in that the closer variables are to each other in the figure, the more highly they tend to be correlated in the tables. The once/many variable, which correlates minimally with the other variables, has coordinates that fall below the values shown on the figures (top panel: Factor $1=.08$, Factor $2=-.25$; bottom panel: Factor $1=.15$, Factor $2=$ -.47 ) as does the age of memory variable, which correlates moderately but uniformly with the other variables (top panel: Factor $1=-.28$, Factor $2=.32$; bottom panel: Factor $1=-.53$, Factor $2=.29)$. For the between-subjects analysis, the first two eigenvalues were 6.25 and 1.98 , which together explain $55 \%$ of the variance. For the withinsubjects analysis, these values are $6.78,1.26$, and $54 \%$.

Multiple regression analyses predicting belief and recollection. We used multiple regression analyses to predict the reliving, back in time, remember/know, and real/ imagine variables with 10 of the remaining 11 variables. Merged/extended was excluded because it had missing values on the $69 \%$ of the memories that were rated as occurring in 1 day. The analyses were done between subjects using the mean ratings of the 50 subjects, and within subjects for each subject individually before aggregating over individual subjects' analyses. Table 5 presents these results. For the between-subjects analysis, the equation with the highest $R^{2}$ that had only variables with a $\beta$ weight significantly different from chance at the .05 level was chosen.

For the within-subjects analyses, regressions were done for each subject separately, and the parameters of the resulting equations were averaged (see Estes, 1956, for a discussion of averaging such linear equations). A $t$ test was performed on the set of $50 \beta$ weights associated with each independent variable to see whether its mean was different from zero. This procedure was first done with all 10 independent variables. Next, the independent variable with the smallest average $\beta$ weight was removed if it was not statistically different from zero. This step was repeated until all remaining $\beta$ weights were statistically significant. We used the .0001 level instead of the .05 level to arrive at a roughly equal number of predictors in the betweenand within-subjects equations in order to facilitate comparisons between them. The change in $p$ level from .05 between subjects to .0001 within subjects indicates the high degree of similarity among the regression equations of the individual subjects.

The regression analyses (Table 5) using the between and within units of analysis are remarkably consistent. The reliving and back in time variables tend to have different predictor variables than the remember/know and real/ imagine variables. First, although the see and setting variables are highly correlated, see enters into all predictions of reliving and back in time, whereas setting never does; by contrast, setting enters into all predictions of remember/ know and real/imagine, whereas see enters only for the within-subjects equations. The difference between being able to "see in my mind" and being able to "recall the setting where it occurred" could be a distinction between imagery and context, or between visual imagery and multimodal spatial imagery (Farah et al., 1988). Second, emotion, or the correlated variable of importance, enters into all regression equations for the reliving and back in time variables with a positive weight, but enters into the two regression equations for the between-subjects analyses for the remember/know and real/imagine variables with a negative weight. In the correlations of Table 3, the betweensubjects correlations between emotion and both remember/ know and real/imagine are small and positive, but once the 

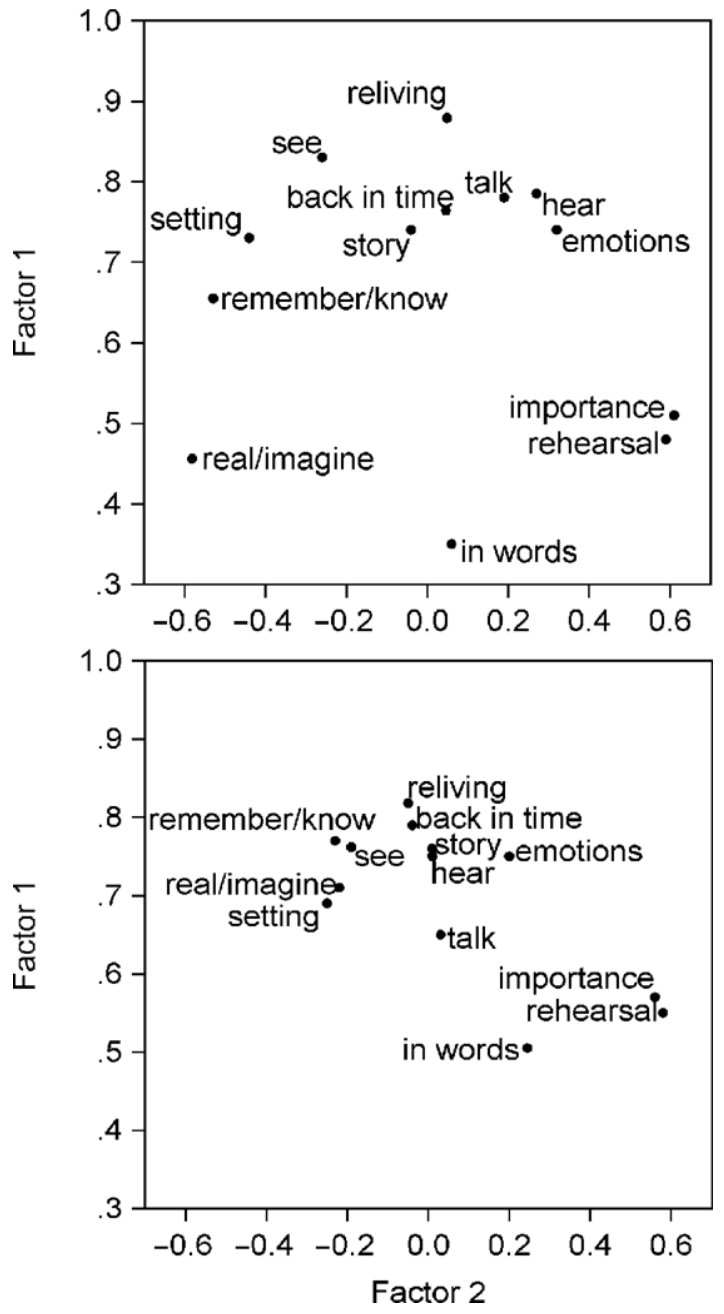

Figure 1. Principal components analysis of Table 3 in the top panel and that of Table 4 in the bottom panel.

effects of setting and story are considered, people who tend to rate their memories as less emotional also tend to rate their memories as remembered as opposed to known, and as real as opposed to imagined. There is one major difference in the within- and between-subjects multiple regressions. The $R^{2}$ values are similar for seven of the eight equations, but it is much lower for the betweensubjects regression of real/imagine. Consistent with the lower between-subjects correlations with real/imagine in Table 3, real/imagine is not as well predicted as an individual differences variable as our other measures.

Differences in within-subjects correlations with belief and recollection. The results of the multiple regressions depend on partial correlations among the full set of variables included. One way to examine the claims made from the regression analyses that does not involve partial correlations among the independent variable is to examine the correlations calculated within each of the 50 subjects. For instance, we can ask whether the within-subjects cor- relation between reliving and see is larger than the correlation between reliving and setting by calculating a matched $t$ test on this difference over all 50 subjects, first using a Fisher's $Z$ transformation to make the distribution less skewed than it is for the correlations (Walker \& Lev, 1953). For this test, the result was significant $[t(49)=3.93, p<$ $.0005]$. For the back in time variable, this test was also significant $[t(49)=2.94, p<.005]$, but it was not significant for the remember/know or real/imagine variables $[t(49)=-0.13$ and $t(47)=0.70$, respectively $]$. Similarly, we can ask whether our clustering of the reliving and back in time variables in one group and the remember/know and real/imagine variables in another is supported by the within-subjects correlations by averaging the correlations of reliving with back in time and remember/know with real/imagine and subtracting from this the average of the four between-cluster correlations (i.e., reliving with remember/know, reliving with real/imagine, back in time with remember/know, back in time with real/imagine) $[t(47)=4.25, p<.0001]$. We can also test to see whether emotions correlates more highly with the variables in the reliving-back in time cluster than the remember/knowreal/imagine cluster $[t(47)=5.15, p<.0001]$. Thus, the claims noted from the multiple regression, which depend on partial correlations among all the variables included, are supported by analyses done on the simple within-subjects correlations that use only the variables in the correlations.

The role of imagery in recollection. For psychologists and philosophers, recollection, or a sense of reliving, is a state of consciousness - autonoetic consciousness, to use Tulving's $(1983,1985)$ term. For many philosophers, but not for many psychologists (see Brewer, 1996, for a review), this state necessarily involves visual imagery. That is, many philosophers treat visual imagery as a defining feature of a recollective, or personal, memory (e.g., Hume, 1739/1978; Locke, 1690/1959). We can ask whether a strong sense of reliving is always accompanied by a visual image. If the philosophers are correct, psychologists may want to consider a view of recollection (and of consciousness in general) in which visual imagery plays a more central role (Greenberg \& Rubin, in press; Rubin, 1995b; Rubin, Burt, \& Fifield, in press; Rubin \& Greenberg, 1998).

Visual imagery (see) correlated highly with and was the best predictor in multiple regression analyses of reliving. To probe the relation between the two measures in more detail, we treated each memory as a separate unit no matter which of the 50 subjects produced it (see Brewer, 1988, for similar analyses). For statistical analyses, this confounds the within- and between-subjects levels of analysis. But we are measuring the strength of a relation by looking for any exceptions to it, a stricter test than showing a significant correlation. Of the 521 responses that were rated above 5 on a scale of "I am reliving the original event," only 8 were rated as below 5 on the scale of being able to "see it in my mind," where 5 is distinctly on both scales. These 8 memories appear to be real exceptions since they came from 6 different subjects. Six of these 8 had a 6 or 7 rating for emotions, 6 had a 6 or 7 rat- 
Table 5

Multiple Regression Analyses for Experiment 1

\begin{tabular}{|c|c|c|c|c|c|c|c|c|c|}
\hline \multirow{2}{*}{$\begin{array}{c}\text { Dependent Units } \\
\text { Variable }\end{array}$} & \multicolumn{8}{|c|}{$\beta$ Weights for Independent Variable } & \multirow[b]{2}{*}{$R^{2}$} \\
\hline & See & Setting & Hear & In Words & Story & Emotions & Importance & $\overline{\text { Age }}$ & \\
\hline \multicolumn{10}{|l|}{ Reliving } \\
\hline Between & .50 & & & .15 & & .45 & & & .76 \\
\hline Within & .33 & & .27 & & .15 & .17 & & & .66 \\
\hline \multicolumn{10}{|l|}{ Back in time } \\
\hline Between & 39 & & & & .30 & & .24 & & .51 \\
\hline Within & .25 & & .13 & & .36 & .14 & & & .62 \\
\hline \multicolumn{10}{|l|}{ Remember/know } \\
\hline Between & & 67 & & & .35 & -.27 & & & .57 \\
\hline Within & .26 & .31 & & & .21 & & & -.11 & .63 \\
\hline \multicolumn{10}{|l|}{ Real/imagine } \\
\hline Between & & .49 & & & .28 & -.32 & & & .30 \\
\hline Within & .19 & .19 & & & .26 & & & -.20 & .54 \\
\hline
\end{tabular}

ing for setting, and all 8 had a 6 or 7 rating for either emotions or setting. Thus, in order to have a high degree of reliving of past events, visual imagery was necessary in all but 8 cases, and these cases had high rating on emotions, setting, or both. The exceptions may be for events that occurred in the dark, or they may be real exceptions in that vivid visual images could have existed but did not. In contrast, of the 955 responses that were rated above 5 on a scale of "I believe the event in my memory really occurred in the way I remember it," 123 were rated as below 5 on the scale of being able to "see it in my mind." Seeing in the mind's eye appears almost necessary (but not sufficient) for reliving, but not at all necessary for believing.

\section{Discussion}

What does remember/know measure? The remember/ know distinction is from earlier work by Tulving (1985) and from the extensive empirical and theoretical work by Gardiner and colleagues and others in laboratory recognition tasks (e.g., Gardiner \& Java, 1990; Gardiner, Ramponi, \& Richardson-Klavehn, 1998; Rajaram \& Roediger, 1997) and in autobiographicalmemory experiments (Hyman, Gilstrap, Decker, \& Wilkinson, 1998; Rybash \& Monaghan, 1999). Our results call into question whether the remember/know judgment is a measure of recollection for autobiographical memories, because under our conditions, remember/know does not have the same pattern of correlations as the other two measures of recollection (reliving and back in time). It follows much more closely the pattern of real/imagine (and our other measures of belief used in Experiment 3: accurate, testify, and persuade). This is a serious problem because Tulving devised both the back in time and the remember/know descriptions to refer to the same underlying distinction. There is not a simple relation between our 7-point scale of remember/know for autobiographical memories and the dichotomous choice used in list-learning experiments. We are asking subjects about complex autobiographical memories from all parts of their life. In the list-learning experiments, subjects are asked about words that were all displayed at about the same time and in the same environment, where terms such as "reliving" and "traveling back in time" may be beyond the range of the subjects' experience. Nonetheless, our work suggests that Tulving's earlier remember/ know distinction and his later description of traveling back in time may be measuring different aspects of autonoetic consciousness.

Episodic versus repisodic memory. All variables correlated at least moderately with some other variables except the merged/extended and the once/many variables, which tended not to correlate with other variables in the study. There is a relation in both the within- and betweensubjects analyses for having a memory for a specific event and judging it to be real as well as having a coherent story for it. However, the strength of these relations is small compared with the other relations obtained.

In his earlier work, Tulving (1972) divided memory into two components, semantic and episodic. Semantic memory stores items such as language rules, word definitions, and general facts. Episodic memory contains the store of "personally experienced unique episodes" that are "distinctive and separate although part of a larger series"; they are "always stored in terms of [their] autobiographicalreference to . . . already existing" memories (Tulving, 1972, pp. 385-387). According to Tulving's early definition, an autobiographicalmemory should be identified as a single, isolated event, not a concatenation of several prior experiences. Brewer (1996) preserved this once-versus-many distinction, but held that both single and repeated events that form a schema can lead to a recollective memory. Neisser (1981) coined the term repisodic memory for the merging of memories of events into one representative event and argued that the rememberer may confuse such repisodic memories with memories of single occurrences. Conway and Pleydell-Pearce (2000) posited that a memory of a single event is constructed on the basis of hierarchical schematic information. In contrast to these schemabased approaches, Tulving's (1972) more atomistic verballearning approach separates the single and multiple occurrences into separate memory stores. Thus, this distinction is at the heart of models that assume storage of individual instances rather than storage of schematically organized memories. That subjects did not judge such memories differently argues that, at least for the variables 
measured, the distinction is not important for the recollection and belief of autobiographical memories.

There are four possible explanations for the absence of a relation between once/many and other variables. First, unlike other measures, once/many is a dichotomous variable and may have less power. Counter to this explanation, there is considerable data to compare (50 subjects with 30 memories each) and there is a reasonable division into the two choices of the dichotomy $(69 \%$ specific vs. $31 \%$ not specific). Second, we have retrospective reports that do not indicate which events were really specific. Third, there is little difference because the general memories are often steps in the search process of obtaining specific memories and are rated as if the specific memory had been found (Conway \& Pleydell-Pearce, 2000; Conway \& Rubin, 1993; Williams, 1996). Fourth, the schematic view may be more applicable in real-world situations with a great range of possible variation among events.

\section{EXPERIMENT 2}

Real/imagine had lower correlations, and lower $R^{2}$ values in multiple regression, in the between- than in the within-subjects analyses. Given that real/imagine is no less variable or reliable a measure than our measures of recollection, we assume that some other factors unrelated to the ones we measured are involved in determining whether an individual tends to believe that all his/her memories are based on reality rather than on partially imagined constructions. The method used here is ideal for searching for such factors, a strategy to which we turn in Experiment 2 using a measure of mood and in Experiment 3 using a measure of dissociation.

In Experiments 2 and 3, we combine individual differences measures of mood and personality with processes involved in autobiographical memory to add converging evidence to the results found in Experiment 1. The individual differences factor that has been studied most extensively in autobiographical memory is mood, especially in relation to depression (Williams, 1996). Mood can affect not only the emotional properties of the memory recalled, but also how specific and detailed it is. We therefore repeated Experiment 1 but added the Beck Depression Inventory (BDI; Beck, Ward, Mendelson, Mock, \& Erbaugh, 1961). We also reduced the number of memories obtained from each subject from 30 to 15 in order to allow time for the BDI.

\section{Method}

Subjects. Sixty-eight Duke University undergraduates who were native speakers of English or who had spoken English for at least 5 years participated. Three subjects were eliminated because they failed to date more than two memories. The average age of the remaining 65 subjects was $18.83(S D=0.97$, range $18-22)$; 37 were female.

Materials and Procedure. The task was identical to that in Experiment 1 except that only 15 of the 30 cue words from Experiment 1 were used, a question on spatial layout was added (see the Appendix for details), and the Autobiographical Memory Questionnaire was followed by the BDI. Half the subjects saw the 15 words
Table 6

Correlations of Autobiographical Memory and Individual Differences Variables

\begin{tabular}{llcl}
\hline \multicolumn{1}{c}{ Variable } & BDI & DES & HPRS \\
\hline Reliving & -.18 & .12 & $.35^{* *}$ \\
Back in time & -.12 & .20 & $.28^{*}$ \\
Remember/know & $-.29^{*}$ & -.23 & .05 \\
Real/imagine & $-.33^{* *}$ & $-.30^{*}$ & .09 \\
Accurate & & $-.26^{*}$ & -.03 \\
Testify & & -.02 & .19 \\
Persuade & $-.28^{*}$ & .14 & .01 \\
See & -.19 & .20 & $.36^{* *}$ \\
Setting & $-.27^{*}$ & .19 & .20 \\
Spatial & $-.28^{*}$ & .05 & .19 \\
Hear & $-.29^{*}$ & $.30^{*}$ & $.39^{* *}$ \\
Talk & -.07 & .12 & $.30^{*}$ \\
In words & $-.38^{* *}$ & .14 & .23 \\
Story & -.22 & .18 & $.31^{*}$ \\
Emotions & .23 & $.24^{*}$ & $.34^{* *}$ \\
Importance & -.03 & .21 & $.28^{*}$ \\
Rehearsal & -.22 & -.05 & $.24^{*}$ \\
Once/many & .17 & .04 & -.17 \\
Merged/extended & .23 & -.05 & -.02 \\
Age of memory & .85 & .85 & .74 \\
Cronbach's alpha &
\end{tabular}

Note-BDI, Beck Depression Inventory; DES, Dissociative Experiences Scale; HPRS, Hong Psychological Reactance Scale.

in the following order and the other half in the reverse order: city, dress, horse, lake, love, mother, party, plant, poetry, kiss, mountain, ocean, sickness, fire, and wine. Subjects were tested in two large groups. At the request of our institutional review board, two BDI questions were eliminated that concerned reduced sexual activity and thoughts of suicide.

\section{Results}

The BDI (with two questions eliminated) had a mean of $8.49(S D=6.30)$ with a range of 0 to 23 . Table 6 shows the correlation of the BDI with each of the questions in the Autobiographical Memory Questionnaire. With three exceptions, which are not significantly different from zero, the correlations are negative; as mood becomes more negative, ratings tend to decrease. The largest correlation is with story; as mood becomes more negative, people find their memories less coherent. The next largest correlation is with real/imagine; belief in one's memories decreases with negative mood. The empirically related measure of remember/know also has a significant correlation, but not the two measures of recollection: reliving and back in time. Thus, the results of correlations with the BDI support our separation of real/imagine and remember/know from reliving and back in time.

Regression equations for reliving, back in time, remember/know, and real/imagine are shown in Table 7 , using the same methods as used in Table 5. One difference was that we did between-subjects analyses with and without the BDI to see both how well the cognitive variables could predict alone to provide a comparison with Experiment 1 and whether the BDI could add any independent predictive value. This occurred only for real/imagine. Thus, we confirmed our initial suspicion that because we could not predict belief in the memory in between-subjects 
Table 7

Multiple Regression Analyses With Depression Measure

\begin{tabular}{|c|c|c|c|c|c|c|c|c|c|}
\hline \multirow{2}{*}{$\begin{array}{l}\text { Dependent Units } \\
\text { Variable }\end{array}$} & \multicolumn{8}{|c|}{$\beta$ Weights for Independent Variable } & \multirow[b]{2}{*}{$R^{2}$} \\
\hline & See & Setting & Hear & Story & Emotions & Importance & Age & Beck & \\
\hline \multicolumn{10}{|l|}{ Reliving } \\
\hline Between & .27 & & .28 & & .33 & .17 & & & .75 \\
\hline Within & .32 & & .33 & & .27 & & & & .68 \\
\hline \multicolumn{10}{|l|}{ Back in time } \\
\hline Between & & & .27 & .25 & .39 & & & & .64 \\
\hline Within & .20 & & & .31 & .34 & & & & .64 \\
\hline \multicolumn{10}{|l|}{ Remember/know } \\
\hline Between & .40 & .39 & & & & -.20 & & & .50 \\
\hline Within & & .37 & & & .36 & & & & .54 \\
\hline \multicolumn{10}{|l|}{ Real/imagine } \\
\hline Between & & .51 & & & & & & & .26 \\
\hline Between + & & .46 & & & & & & -.24 & .32 \\
\hline Within & .22 & .19 & & & .17 & & -.22 & & .64 \\
\hline
\end{tabular}

Note-Between + , between-subjects analysis including the Beck Depression Inventory.

analyses, it must be able to be predicted by other measures. In other respects, the results are similar to those of Experiment 1.

\section{EXPERIMENT 3}

Experiment 3 is a near replication of Experiment 2 except that we added questions about belief and used different individual differences measures. Experiments 1 and 2 could be criticized for having only one measure of belief that had clear face validity. We therefore devised and included three more measures to assess belief in the accuracy of the event in different ways (testify, persuade, and accurate; see the Appendix for details). A strict criterion for belief is whether you would testify in a court of law about the memory. A test of the strength of the belief is whether you could be persuaded by another witness to the event who had a different memory. Another aspect of belief in the accuracy of the memory is accuracy - whether your memory is as accurate as that of a neutral observer.

We included the Dissociative Experiences Scale (DES), a standardized test of dissociation and one of the most commonly used tests in individual difference studies of autobiographical memory (Read \& Winograd, 1998). Items of the DES run from $0 \%$ to $100 \%$. The test yields internally consistent and stable scores (Bernstein \& Putnam, 1986; Carlson \& Putnam, 1993). Read and Winograd, reviewing Hyman and Billings (1998) and several others in a special edition of Applied Cognitive Psychology, noted that the DES correlated positively with susceptibility to memory errors in 8 of 10 experiments. Here we do not measure memory errors, but ask whether people know about their own tendency to be susceptible to errors. Since many items on the DES ask for the percentage of times that one's memory is found to be inaccurate, this is a reasonable expectation. We also included the Hong Psychological Reactance Scale (HPRS; Hong \& Faedda, 1966), which measures the personality construct of psychological reactance (Brehm \& Brehm, 1981). Items on the 11-item scale are rated from 1 to 5 and include "I become angry when my freedom of choice is restricted," "I find contradicting others stimulating," "I resist attempts of others to influence me," and "I consider advice from others an intrusion." Because people often discover that not all their memories are $100 \%$ accurate in social interactions, we speculated that the psychological reactance might also tap people's belief that their memories were accurate.

\section{Method}

Subjects. Sixty-five Duke University undergraduates, who were native speakers of English or who had spoken English for at least 8 years, participated. Their average age was $18.55(S D=0.98$, range 16-21); 41 were female.

Materials and Procedure. The task was identical to that of Experiment 2 except that three ratings scales to assess belief were added, and the Autobiographical Memory Questionnaire was followed by the DES and HPRS.

\section{Results}

The DES had a mean of $17.03(S D=8.35)$ with a range of 5.71 to 37.86; this mean is in the range found in tests of late adolescents (Carlson \& Putnam, 1993). The HPRS had a mean of $3.06(S D=0.54)$ with a range of 2.00 to 4.73 .

Table 6 shows the correlation of the DES and HPRS with each of the questions in the Autobiographical Memory Questionnaire. Like the BDI, the DES has little effect on our two measures of recollection, reliving and back in time, but does correlate with two measures of belief: reall imagine and accurate. With greater dissociative experience, belief in one's memories decreases. The HPRS was intended to also tap belief rather than the recollection, but did exactly the opposite and thus shows that different personality variables can affect different aspects of the phenomenology of memory. The HPRS does not correlate with measures of belief in the accuracy of the memory but does correlate with reliving and back in time, our two measures of recollection, and several variables that correlate highly with them, including see, hear, and emotions. Because the HPRS has many correlations with variables that enter as independent variables in the regression equations 
for reliving and back in time and because reliving and back in time are already well predicted in between-subjects multiple regressions, the HPRS does not enter into any of the multiple regression analyses that follow.

Regression coefficients are shown in Table 8, using the same methods as were used in Tables 5 and 7 . The results replicate those of Experiments 1 and 2. Again the withinand between-subjects analyses are remarkably consistent, with the one exception that the between-subjects analysis for belief predicts much less variance than the within analysis. This difference in predictive value held individually for all four measures of belief in the accuracy of the memories: real/imagine, accurate, testify, and persuade, as well as for remember/know. The average for these five measures was an $R^{2}$ of .58 within subjects versus .15 between subjects. As in Experiments 1 and 2, reliving and back in time tend to have different predictor variables than do remember/ know and real/imagine, with accurate, testify, and persuade following the pattern of real/imagine. In particular, see (and to a lesser degree hear) enters into most predictions of reliving and back in time in all three experiments, whereas setting (and spatial) never does but instead enters into predictions of the four measures of belief. Also, as in Experiment 1, emotion and the correlated variable of importance have higher $\beta$ weights for reliving and back in time than for the four measures of belief. Thus, the distinction between belief and recollection is again supported.

\section{GENERAL DISCUSSION}

This paper provides the most comprehensive study of the relations among the variables commonly used in the study of autobiographicalmemory. By having many people each rate many memories on many scales, it was possible to provide a collection of analyses that examined the nomothetic relations among scales within individuals as well as the idiographic relations between individuals. Doing so provided an indication of how the measures we use relate to each other and how judgments of recollection and belief differed.

Before beginning a general discussion, we need to discuss one methodological issue. One disadvantage of the repeated testing of subjects required by our analyses is that the subjects may gain expertise, tire, or change criteria during the task. Moreover, because ratings are intermixed with recall, the memories recalled might change because subjects search for memories on the basis of the scales. Having subjects commit to all memories by giving a brief description before any ratings would solve this last problem, and is often used as a strategy when dates are the only measure taken (Rubin, 1982). However, with the more phenomenological variables used here, it is not clear that the memory would be recalled in the same way if the subjects were to return to descriptions of the memories. To ensure that our results were not unduly affected by any of these problems, we compared the first and last five memories of each of the 183 subjects in Experiments 1,2, and 3 . Of the 13 7-point rating scales, 7 increased and 6 decreased in magnitude, the mean change of the 13 scales was -0.03 on a 7 -point scale, and the mean absolute change was 0.14 . Thus, there was no clear drift or large change in the magnitude of the ratings. In terms of the variances, 5 scales increased and 8 decreased, the mean ratio of early to late variances was 1.00 , and the mean ratio of the biggest to the smallest variance, no matter whether the biggest variance was early or late, was 1.08 . Thus, there was no clear change in variance. A test more directly related to our conclusions is to perform exactly the same multiple regressions as were done in our between analyses but using only the very first memory instead of the average of all memories. Here the effects of repeated testing are nonexistent. These analyses are very similar to the ones given earlier, though the $R^{2}$ values are a bit lower, probably because the data are noisier due to fewer observations. The equations are reliving $=.24$ see +.32 hear + .19 emotions +.17 rehearse, $R^{2}=.44 ;$ back in time $=.30$ talk +.25 story +.17 importance, $R^{2}=.29$; remember $/$ know $=.28$ see +.19 setting +.16 story -.25 age of memory, $R^{2}=.40$; and real/imagine $=.15$ see +.27 setting -.33 age of memory, $R^{2}=.32$.

What properties predict the degree to which a memory will be recollected or believed? Over three near replications, we obtained the same basic answers. In multiple regressions, measures of belief were better predicted by measures of spatial imagery, whereas measures of recollection were better predicted by measures of visual imagery, auditory imagery, and emotions. Having the memory form a coherent story predicts both recollection and belief. These findings are consistent with work by Johnson and colleagues showing that conceptual rather than perceptual measures are more consistent predictors of judgments of real versus imagined events. This is not to claim that vividness of imagery does not have an effect on belief. In the within-subjects correlations of Table 4, see and setting have similar correlations with real/imagine, false memories typically have less imagery than real ones (Loftus, Korf, \& Schooler, 1989; Mather et al., 1997; Stern \& Rotello, 2000), and imagining an event, which involves vividness and setting, increases belief in its memory (Garry \& Polaschek, 2000; Mazzoni \& Memon, 2003). It is just that the effect of setting appears to be larger.

In general, the magnitudes of the between-subjects correlations in Table 3 and the average of the within-subjects correlations in Table 4 are similar, and the weights in the within- and between-subjects multiple regressions in Tables 5, 7, and 8 are similar. But this does not mean we have repeated the same analyses. The between-subjects analyses answer individual differences questions about the relations among general tendencies in people. The averages of the within-subjects analyses answer more prototypically cognitive questions about how each individual processes information. For example, the observation that people who relive their memories more also have good visual images for them is at a different level of analysis from the observation that for any particular person the memo- 
Table 8

Multiple Regression Analyses With Personality Measures

\begin{tabular}{|c|c|c|c|c|c|c|c|c|c|c|c|}
\hline \multirow{2}{*}{$\begin{array}{c}\text { Dependent Units } \\
\text { Variable }\end{array}$} & \multicolumn{10}{|c|}{$\beta$ Weights for Independent Variable } & \multirow[b]{2}{*}{$R^{2}$} \\
\hline & See & Setting & Spatial & Hear & Story & Emotions & Importance & Rehearse & Age & DES & \\
\hline \multicolumn{12}{|l|}{ Reliving } \\
\hline Between & .19 & & & .27 & & .29 & .24 & & & & .55 \\
\hline Within & .38 & & & & & .34 & & .15 & & & 63 \\
\hline \multicolumn{12}{|l|}{ Back in time } \\
\hline Between & & & & .27 & .28 & & .27 & & & & .41 \\
\hline Within & .22 & & & & .40 & .20 & & & & & .59 \\
\hline \multicolumn{12}{|l|}{ Remember/know } \\
\hline Between & .54 & & -.27 & & & & & & & & .20 \\
\hline Between + & .54 & & -.31 & & & .26 & & & & -.36 & .36 \\
\hline Within & .30 & & & & .30 & & & & -.20 & & 62 \\
\hline \multicolumn{12}{|l|}{ Real/imagine } \\
\hline Between & & .29 & & & & & & & & & .08 \\
\hline Between + & & .36 & & & & & & & & -.37 & .21 \\
\hline Within & .24 & & .18 & & .27 & & & & & & .54 \\
\hline \multicolumn{12}{|l|}{ Accurate } \\
\hline Between & & .38 & & & & & & & & & .15 \\
\hline Between + & & .45 & & & & & & & & -.34 & .26 \\
\hline Within & & & .34 & & .29 & & & & & & .45 \\
\hline \multicolumn{12}{|l|}{ Testify } \\
\hline Between & .25 & & & & .31 & & & & & & .23 \\
\hline Within & .19 & & .18 & & .26 & .15 & & & -.19 & & .75 \\
\hline \multicolumn{12}{|l|}{ Persuade (reverse) } \\
\hline Between & .26 & & & & & & & & & & .07 \\
\hline Within & & & .28 & & .38 & & .14 & & & & .56 \\
\hline
\end{tabular}

ries he/she relives most are also the ones that have the most visual imagery. There is no mathematical necessity for these two observations to have similar correlations.

An unexpected and especially interesting finding is that recollection was predicted equally well in within- and between-subjects analyses, but belief consistently had smaller correlations and multiple regression predictions between subjects, showing that individual differences in the cognitive factors we measured could better account for individual differences in recollection than for individual differences in belief. In most research in cognitive psychology, within- and between-subjects analyses are freely mixed. We separated them, and for belief, we found somewhat different answers. Although the same variable tended to predict belief in both analyses, the between-subjects correlations were much smaller. Whether people tend to believe their memories are accurate overall is not determined by cognitive variables of the kind we measured. It cannot be the case that cognitive variables are just better at predicting behavior within than between individuals; the difference in predictive value for belief was not present for recollection.

If this individual difference in belief in memories is to be explained, the answer is outside our cognitive measures, and so we looked at the standardized tests we thought might be helpful. We examined one measure of mood, the Beck Depression Index, one measure of dissociation, the Dissociative Experience Scale, and the Hong Psychological Reactance Scale. In multiple regression analyses, the first two added independent predictive value for belief; none added predictive value for recollection, though the reactance measure had moderate correlations with measures of recollection and the variables that predict it. The standardized tests reinforced our empirical distinction between recollection and belief by correlating either with measures of recollection or with measures of belief, but not both.

One place where our findings may challenge the literature is that remember/know judgments made on autobiographical memories were more closely related to measures of belief than recollection. This occurred repeatedly over the three experiments. One could argue that this finding has no direct bearing on the dichotomous scale of remember/know as used in laboratory tasks. Separate tests would have to be made there. But it does point to weakness in current work in cognitive psychology. Not including our remember/know question, we had two clear measures of recollection and four of belief. The distinctions we made between them on theoretical grounds were supported empirically. But there were still differences between the two measures of recollection and among the four measures of belief. What is really needed for autobiographical memory, and also in the laboratory measures of recollection, is the formulation of many different variants of the theoretical question of interest followed by empirical testing of them. We have only shown the necessity for such work, not resolved questions of how the various measures of the same underlying concept relate and which offers the purest measure of the theoretical concepts of interest. We have demonstrated a method capable of pro- 
ducing such understanding and provided a comprehensive set of findings based on the measures currently available.

\section{REFERENCES}

BADDELEY, A. D. (1992). What is autobiographicalmemory? In M. A. Conway, D. C. Rubin, H. Spinnler, \& W. A. Wagenaar (Eds.), Theoretical perspectives on autobiographical memory (pp. 13-29). Dordrecht: Kluwer.

BAHRICK, H. P. (1979). Maintenance of knowledge: Questions about memory we forgot to ask. Journal of Experimental Psychology: General, 108, 296-308.

Beck, A. T., Ward, C. H., Mendelson, M., Mock, J., \& Erbaugh, J. (1961). An inventory for measuring depression. Archives of General Psychiatry, 4, 561-571.

Bernstein, E. M., \& Putnam, F. W. (1986). Development, reliability and validity of a dissociation scale. Journal of Nervous \& Mental Disease, 174, 727-734.

Berntsen, D., Willert, M., \& Rubin, D. C. (2003). Splintered memories or vivid landmarks? Reliving and coherence of traumatic memories in PTSD. Applied Cognitive Psychology, 17, 675-693.

BREHM, S. S., \& BREHM, J. W. (1981). Psychological reactance: A theory of freedom and control. New York: Academic Press.

BREWER, W. F. (1988). Memory for randomly sampled autobiographical events. In U. Neisser \& E. Winograd (Eds.), Remembering reconsidered: Ecological and traditional approaches to the study of memory (pp. 21-90). Cambridge: Cambridge University Press.

BREWER, W. F. (1996). What is recollective memory? In D. C. Rubin (Ed.), Remembering our past: Studies in autobiographical memory (pp. 19-66). Cambridge: Cambridge University Press.

BRYK, A. S., \& RAUDENBUSH, S. W. (1992). Hierarchical linear models: Applications and data analysis methods. Newbury Park, CA: Sage.

Carlson, E. B., \& Putnam, F. W. (1993). An update on the Dissociative Experiences Scale. Dissociation, 6, 16-27.

Cattell, R. B. (1952). The three basic factor-analytic research designs: Their interrelations and derivatives. Psychological Bulletin, 49, 499520.

Cavanaugh, J. C., Feldman, J. M., \& Hertzog, C. (1998). Memory beliefs as social cognition: A reconceptualization of what memory questionnaires assess. Review of General Psychology, 2, 48-65.

Christianson, S.-A, \& SAFEr, M. A. (1996). Emotional events and emotions in autobiographical memories. In D. C. Rubin (Ed.), Remembering our past: Studies in autobiographicalmemory (pp. 218-243). Cambridge: Cambridge University Press.

Conee, E. (1998). Epistemology of memory. In C. Edward (Ed.), Routledge encyclopedia of philosophy. New York: Routledge.

Conway, M. A., \& Pleydell-Pearce, C. W. (2000). The construction of autobiographical memories in the self-memory system. Psychological Review, 107, 261-268.

Conway, M. A., \& RUbin, D. C. (1993). The structure of autobiographical memory. In A. E. Collins, S. E. Gathercole, M. A. Conway, \& P. E. Morris (Eds.), Theories of memory (pp. 103-137). Hove, U.K.: Erlbaum.

Cronbach, L. J. (1957). Two disciplines of scientific psychology.American Psychologist, 12, 671-684.

Crovitz, H. F., \& Schiffman, H. (1974). Frequency of episodic memories as a function of their age. Bulletin of the Psychonomic Society, 4, 517-518.

Ericsson, K. A., \& Simon, H. A. (1993). Protocol analysis: Verbal reports as data (Rev. ed.). Cambridge, MA: MIT Press, Bradford Books.

EsTES, W. K. (1956). The problem of inference from curves based on group data. Psychological Bulletin, 53, 134-140.

Farah, M. J., Hammond, K. M., Levine, D. N., \& Calvanio, R. (1988). Visual and spatial mental imagery: Dissociable systems of representation. Cognitive Psychology, 20, 439-462.

GARDINER, J. M., \& JAVA, R. I. (1990). Recollective experience in word and nonword recognition. Memory \& Cognition, 18, 23-30.

Gardiner, J. M., Ramponi, C., \& Richardson-Klavehn, A. (1998). Experiences of remembering, knowing, and guessing. Consciousness \& Cognition, 7, 1-26.

Garry, M., \& PolascheK, D. L. L. (2000). Imagination and memory. Current Directions in Psychological Science, 9, 6-10.
Ginet, C. (1980). Knowing less by knowing more. Midwest Studies in Philosophy, 5, 51-60.

Greenberg, D. L., \& Rubin, D. C. (in press). The neuropsychology of autobiographical memory. Cortex.

Grice, H. P. (1975). Logic and conversation. In P. Cole \& J. L. Morgan (Eds.), Syntax and semantics (Vol. 3). New York: Academic Press.

Hong, S. M., \& FAedDA, S. (1996). Refinement of the Hong Psychological Reactance Scale. Educational \& Psychological Measurement, 56, 173-182.

Hume, D. (1978). A treatise of human nature. Oxford: Oxford University Press, Clarendon Press. (Original work published 1739)

Hyman, I. E., JR., \& Billings, F. J. (1998). Individual differences and the creation of false childhood memories. Memory, 6, 1-20.

Hyman, I. E., Jr., Gilstrap, L. L., Decker, K., \& Wilkinson, C. (1998). Manipulating remember and know judgements of autobiographical memories: An investigation of false memory creation. Applied Cognitive Psychology, 12, 371-386.

Johnson, M. K., Foley, M. A., Suengas, A. G., \& Raye, C. L. (1988). Phenomenal characteristics of memories for perceived and imagined autobiographical events. Journal of Experimental Psychology: General, 117, 371-376.

Johnson, M. K., Hashtroudi, S., \& Lindsay, D. S. (1993). Source monitoring. Psychological Bulletin, 114, 3-28.

Johnson, M. K., \& RAYE, C. L. (1981). Reality monitoring. Psychological Review, 88, 67-85.

LARSEN, S. F. (1998). What is it like to remember? On phenomenal qualities of memory. In C. P. Thompson, D. J. Herrmann, D. Bruce, J. D. Reed, D. G. Payne, \& M. P. Toglia (Eds.), Autobiographicalmemory: Theoretical and applied perspectives (pp. 163-190). Mahwah, NJ: Erlbaum.

Larsen, S. F., Schrauf, R. W., Fromholt, P., \& Rubin, D. C. (2002). Inner speech and bilingual autobiographical memory: A PolishDanish cross-cultural study. Memory, 10, 45-54.

LOCKE, J. (1959). An essay concerning human understanding. New York: Dover. (Original work published 1690)

Loftus, E. F., Korf, N. L., \& Schooler, J. W. (1989). Misguided memories: Sincere distortions of reality. In J. C. Yuille (Ed.), Credibility assessment (pp. 153-173). Boston: Kluwer.

Mather, M., Henkel, L. A., \& Johnson, M. K. (1997). Evaluating characteristics of false memories: Remember/know judgments and memory characteristics questionnaire compared. Memory \& Cognition, 25, 826-837.

Mazzoni, G., \& Memon, A. (2003). Imagination can create false autobiographical memories. Psychological Science, 14, 186-188.

McNally, R. J., Litz, B. T., Prassas, A., Shin, L. M., \& Weathers, F. W. (1994). Emotional priming of autobiographical memory in posttraumatic stress disorder. Cognition \& Emotion, 8, 351-367.

NeISSER, U. (1981). John Dean's memory: A case study. Cognition, 9, 1-22. Nesselroade, J. R., \& Molenaar, P. C. M. (1999). Pooling lagged covariance structures based on short, multivariate time series for dynamic factor analysis. In R. H. Hoyle (Ed.), Statistical strategies for small sample research (pp. 224-250). Thousand Oaks, CA: Sage.

Pillemer, D. B. (1998). Momentous events, vivid memories: How unforgettable moments help us understand the meaning of our lives. Cambridge, MA: Harvard University Press.

Rajaram, S., \& Roediger, H. L., III (1997). Remembering and knowing as states of consciousness during retrieval. In J. D. Cohen \& J. W. Schooler (Eds.), Scientific approaches to consciousness (pp. 213-240). Mahwah, NJ: Erlbaum.

ReAD, D. J., \& Winograd, E. (1998). Introduction. Applied Cognitive Psychology, 12, S1-S4.

ReISBERG, D. (Ed.) (1992). Auditory imagery. Hillsdale, NJ: Erlbaum. Rubin, D. C. (1980). Fifty-one properties of 125 words: A unit analysis of verbal behavior. Journal of Verbal Learning \& Verbal Behavior, 19, 736-755.

RuBIN, D. C. (1982). On the retention function for autobiographical memory. Journal of Verbal Learning \& Verbal Behavior, 21, 21-38.

RubIN, D. C. (1995a). Memory in oral traditions: The cognitive psychology of epic, ballads, and counting-out rhymes. New York: Oxford University Press.

Rubin, D. C. (1995b). Stories about stories. In R. S. Wyer, Jr. (Ed.), Knowledge and memory: The real story (pp. 153-164). Hillsdale, NJ: Erlbaum. Rubin, D. C. (1998). Beginnings of a theory of autobiographical re- 
membering. In C. P. Thompson, D. J. Herrmann, D. Bruce, J. D. Reed, D. G. Payne, \& M. P. Toglia (Eds.), Autobiographicalmemory: Theoretical and applied perspectives (pp. 47-67). Mahwah, NJ: Erlbaum.

Rubin, D. C. (2002). Autobiographical memory across the lifespan. In P. Graf \& N. Ohta (Eds.), Lifespan development of human memory (pp. 159-184). Cambridge, MA: MIT Press.

Rubin, D. C., \& BERnTSEN, D. (2003). Life scripts help to maintain autobiographical memories of highly positive, but not highly negative, events. Memory \& Cognition, 31, 1-14.

Rubin, D. C., Burt, C. D. B., \& Fifield, S. J. (in press). An experimental manipulation of the phenomenology of memory. Memory \& Cognition.

Rubin, D. C., Feldman, M. E., \& Beckham, J. C. (in press). Reliving, emotions, and fragmentation in the autobiographical memories of veterans diagnosed with PTSD. Applied Cognitive Psychology.

Rubin, D. C., \& Greenberg, D. L. (1998). Visual memory-deficit amnesia: A distinct amnesic presentation and etiology. Proceedings of the National Academy of Sciences, 95, 5413-5416.

Rubin, D. C., \& GReEnberG, D. L. (2003). The role of narrative in recollection: A view from cognitive and neuropsychology. In G. Fireman, T. McVay, \& O. Flanagan (Eds.), Narrative and consciousness: Literature, psychology, and the brain (pp. 53-85). New York: Oxford University Press.

Rubin, D. C., Groth, L., \& Goldsmith, D. (1984). Olfactory cuing of autobiographical memory. American Journal of Psychology, 97, 493507.

Rubin, D. C., \& Schulkind, M. D. (1997). Distribution of important and word-cued autobiographical memories in 20-, 35-, and 70-year-old adults. Psychology \& Aging, 12, 524-535.

Ry bash, J. M., \& Monaghan, B. E. (1999). Episodic and semantic contributions to older adults' autobiographical recall. Journal of General Psychology, 126, 85-96.

Schooler, J. W., \& Fiore, S. M. (1997). Consciousness and the limits of language: You can't always say what you think or think what you say. In J. D. Cohen \& J. W. Schooler (Eds.), Scientific approaches to consciousness: Carnegie Mellon symposium on cognition (pp. 241-257). Mahwah, NJ: Erlbaum.

Schrauf, R. W. (2000). Bilingual autobiographical memory: Experimental studies and clinical cases. Culture \& Psychology, 6, 387-417.
Schrauf, R W., \& RUBin, D. C. (1998). Bilingual autobiographical memory in older adult immigrants: A test of cognitive explanations of the reminiscence bump and the linguistic encoding of memories. Journal of Memory \& Language, 39, 437-457.

Schrauf, R. W., \& RubIN, D. C. (2000). Internal languages of retrieval: The bilingual encoding of memories for the personal past. Memory \& Cognition, 28, 616-623.

SchWARZ, N. (1990). Assessing frequency reports of mundane behaviors: Contributions of cognitive psychology to questionnaire construction. In C. Hendrick \& M. S. Clark (Eds.), Review of personality and social psychology: Vol. 11. Research methods in personal and social psychology (pp. 98-119). Beverly Hills, CA: Sage.

Sheen, M., Kemp, S., \& Rubin, D. C. (2001). Twins dispute memory ownership: A new false memory phenomenon. Memory \& Cognition, 29, 779-788.

Stern, E. R., \& Rotello, C. M. (2000). Memory characteristics of recently imagined events and real events experienced previously. American Journal of Psychology, 113, 569-599.

Tulving, E. (1972). Episodic and semantic memory. In E. Tulving \& W. Donaldson (Eds.), Organization of memory (pp. 381-403). New York: Academic Press.

Tulving, E. (1983). Elements of episodic memory. Oxford: Oxford University Press.

Tulving, E. (1985). Memory and consciousness. Canadian Psychology, 25, 1-12.

UNDERWOOD, B. J. (1975). Individual differences as a crucible in theory construction. American Psychologist, 30, 128-134.

Walker, H. M., \& Lev, J. (1953). Statistical inference. New York: Holt. Wheeler, M. A., Stuss, D. T., \& Tulving, E. (1997). Toward a theory of episodic memory: The frontal lobes and autonoetic consciousness. Psychological Bulletin, 121, 331-354.

Williams, J. M. G. (1996). Depression and the specificity of autobiographical memory. In D. C. Rubin (Ed.), Remembering our past: Studies in autobiographicalmemory (pp. 244-267). Cambridge: Cambridge University Press.

WRIGHT, D. B. (1998). Modelling clustered data in autobiographicalmemory research: The multilevel approach. Applied Cognitive Psychology, 12, 339-357. 
APPENDIX

The Autobiographical Memory Questionnaire Used in Experiments 1-3

All questions used in any of the experiments are listed. The exact questions and the order of presentation are given in each Procedure section. The words underlined in the appendix were underlined and set in bold in the booklet to ensure that the high end of the scale would be noted. Questions marked with an asterisk were used in all experiments.

For questions a-g the scales ranged from 1 (not at all) to 3 (vaguely) to 5 (distinctly) to 7 (as clearly as if it were happening right now).

a.* As I remember the event, I feel as though I am reliving the original event.

b.* As I remember the event, I can hear it in my mind.

c.* As I remember the event, I can see it in my mind.

d.* As I remember the event, I or other people are talking.

e. As I remember the event, I know its spatial layout.

f.* As I remember the event, I can feel now the emotions that I felt then.

g.* As I remember the event, I can recall the setting where it occurred.

For questions $\mathrm{h}-\mathrm{m}$, the scales ranged from 1 (not at all) to 3 (vaguely) to 5 (distinctly) to 7 (as much as any memory).

h.* Sometimes people know something happened to them without being able to actually remember it. As I think about the event, I can actually remember it rather than just knowing that it happened.

i.* As I remember the event, it comes to me in words.

$\mathrm{j}$. * As I remember the event, I feel that I travel back to the time when it happened, that I am a subject in it again, rather than an outside observer tied to the present.

$\mathrm{k}$ * As I remember the event, it comes to me in words or in pictures as a coherent story or episode and not as an isolated fact, observation, or scene.

1.* This memory is significant for my life because it imparts an important message for me or represents an anchor, critical juncture, or a turning point.

m. Would you be confident enough in your memory of the event to testify in a court of law.

The remaining questions had unique scales:

n. * I believe the event in my memory really occurred in the way I remember it and that I have not imagined or fabricated anything that did not occur. (Scale: $1=100 \%$ imaginary; $7=$ $100 \%$ real)

o.* Since it happened, I have thought or talked about this event. (Scale: $1=$ not at all; $7=$ as often as any event in my life)

p. If another witness to the event, who you generally trusted, existed and told you a very different account of the event to what extent could you be persuaded that your memory was wrong. (Scale: $1=$ not at all; $3=$ in some details; $5=$ in some main points; $7=$ completely)

q. * To the best of your knowledge, is the memory of an event that occurred once at one particular time and place, a summary or merging of many similar or related events, or for events that occurred over a fairly continuous extended period of time lasting more than a day? (Scale: 1 = once; 2 = merging; 3 = extended)

Responses to this question were recoded to produce two scales. Once/many had a value of 1 if the subject judged the memory to take place within a single day and 0 if it took longer. Merged/extended had a value of 0 if the event lasted longer than a day and was extended in a fairly continuous manner over a period of time and 1 if it was the merging of many discrete events.

r. * Please date the memory (month/day/year) as accurately as you can. Please fill in a month, day, and year even if you must estimate. If the memory extended over a period of time, report the approximate middle of the period. (scored as retention interval in days)

s. To what extent is your memory of the event distorted by your beliefs, motives, and expectations rather than an accurate reflection of the event as a neutral observer would report it? $(1=100 \%$ distorted $;=100 \%$ accurate $)$ 